\title{
The relationship between emotional intelligence and various psychological quotients
}

\author{
Shrutika verma \\ Amity Business School
}

\begin{abstract}
The purpose of this study is to critically analyze the relationship between emotional intelligence and various psychological quotients. This research is qualitative in nature and based on reviewing the previous studies done on emotional intelligence $(E Q)$ and the various quotients. The different quotients taken into consideration are intelligence quotient (IQ), Meaning quotient (MQ), Global Quotient (GQ), Motivational quotient $(M Q)$, Experience quotient $(X Q)$, People quotient $(P Q)$, Learning quotient $(L Q)$, Cultural quotient $(C Q)$, Consciousness quotient $(C Q)$, Reputation quotient (RQ), Spiritual quotient (SQ), Adversity quotient $(A Q)$, and Empathy quotient (EQ). After analyzing the literature, a brainstorming session was done to conclude a critical review.
\end{abstract}

Keywords: emotional intelligence; adversity quotient, intelligence quotient;People quotient; Adversity quotient; Empathy quotient.

\section{Introduction}

Emotional Intelligence (EI) is the ability of the person to capture, realize, control and understand the emotions of self as well as others to handle interpersonal relationships. The various quotients in question are Intelligence Quotient (IQ) is important for analyzing the employees' capabilities and their behaviors to perform the particular task. It determines how bright you are and the level of the analytical skills. Motivational Quotient (MQ) determines the motivation level and how driven a person is to achieve and grow in life. People Quotient $(\mathrm{PQ})$ is determined by how well a person handles himself and work with others, it is also referred to as EQ. Learning Quotient (LQ) determined by how deftly a person adopts new skills and behaviors. Meaning Quotient (MQ) can be defined as the degree to which employees view their work ashaving meaning or impact. It plays a great role when defining success and deciding whether the people would perform at peak levels. Cultural quotient (CQ) depicts the capability to relate and the ability to work effectively across all cultures. Empathy quotient (EQ) judges what people are thinking, how they are feeling, and their intentions. Consciousness quotient (CQ) depicts the pro-environmental behaviors. Adversity Quotient (AQ) measures the ability of person to deal with adversities in life. Spiritual quotient (SQ) Spiritual Quotient is the mental faculty which enables a person to overcome the limitations that are the traits of IQ and EQ. Reputation Quotient (RQ) measures the corporate reputation and captures all the stakeholder's interests in terms of reputation of organization.

\section{Literature review}

Cranston (2013) focused on employee motivation and productivity while focusing on meaning quotient and how to focus particularly on strategies for increasing MQ of employees. Gondal (2013) studied the cognitive and emotional aspects of intelligence and its related behavioral and psychological outcomes on employees' performance.It was found that IQ alone is not sufficient for the success of employees but it was also to be noted emotional Intelligence has a significant relationship with employees' performance. Thus, revealing that EI is more important than Intelligence quotient at workplace. Ghabanchi (2014) studied the impact of both IQ and emotional intelligence on reading comprehension in Iran using the following tests: Bar-On's emotional intelligence inventory (EQ-i), Raven's Advanced Progressive Matrices, and the reading comprehension portion of the TOEFL. It was found that IQ and reading comprehension have a stronger relationship than emotional intelligence and reading comprehension which showed only a small correlation. Thus, it was concluded that IQ is more important for reading comprehension. Stone (2009) focused on EI vs IQ. EI was concluded as a significant factor to become more effective leader and manager. She focused on Emotional Intelligence Quotient and the ability to maintain and recognize emotions. Checa (2015) studied the relationship between IQ and EI and cognitive control processes. A negative correlation between IQ and control processes was observed, similarly a negative correlation was observed between EI and control processes. Imlahi (2015) focused on variables that affect IQ and EQ. The variables considered were: Gender, sleep hours, watching television hours, Grades, Parentless, Sport, Breakfast and Problems at home. Lievens (2009) focused on relationship between Practical intelligence, Emotional intelligence and Social intelligence. This whole construct gave the precursors as Individual diff erence (KSAOs) with all three working together interlinkingto increase job performance. 
Horn (2013) focused on reputation quotient and its benefits on organization especially focusing on following aspects of reputation quotient: Emotional Appeal, Products and Services, Vision and Leadership, Workplace and Environment, Social and Environmental Responsibility and Financial Performance Rockstuhl et al (2011) emphasized on the cultural intelligence especially in case of cross-border responsibilities where they found that general intelligence predicted both domestic and cross-border leadership effectiveness whereas EI was a stronger predictor of domestic leadership effectiveness and cultural intelligence was a stronger predictor of cross-border leadership effectiveness. Ersoy (2014) also studiedthe role of cultural intelligence in crosscultural leadership effectiveness where they found that expatriate leaders' CQ positively is greatly impacted by their cross-cultural leadership effectiveness.VanderPal (2016) focused on IQ, Global quotient (GQ) and EI. The paper focused on IQ, emotional intelligence (EI) and leadership behavior are complemented by cultural intelligence (CQ) in achieving a high global quotient (GQ).

Soebyakto (2012) examined the drivers of personal quality of corporate managers based on the examination of intelligence, emotional, and spiritual quotients (IESQ) and mediated by internal locus of control. A significant positiverelationship between IESQ and personal quality.they also found that managers have more of EQ and SQ rather than IQ. SQ seemed placed highest portion when mediated with locus of control in the study it showed that most of managers are Moslem. Suan ChinT et al (2011) focused on the role of EI and SQ in the workplace. It was found that both EI and SQ are important in the workplace environment. EI would help the employees to express their emotions fully while SQ helps to apply the spiritual resources carefully. Fallah et al (2015) investigated emotional quotient and spiritual quotient and studying whether human emotions and feelings can contribute to the Islamic ethics or not. It was found that people with high SQ lead a healthy spiritual and psychic life. It was also concluded that individuals who use their spiritual motivations and have high emotional quotient, have a better competitive advantage than those who do not. Sen et al (2015) studied the relationship between managerial effectiveness and spiritual quotient, concluding a positive relationship.Rowelie et al (2015) intended to study whether EI and adversity quotient (AQ) as predictors of academic performance which would help in improving the educational system for globally competitive world. Their study concluded aninsignificant relationship both on EI and AQ towards academic performance. Maureen M. (2015) determined the relationship between Adversity Quotient and Social Skills, it was concluded a significant relationship between AdversityQuotient and Social Skills.Daloos (2015) studied the relationship between emotionalintelligence and adversity quotient of helping professionals. It was concluded that EI behaviors are evident with all EI skills to wit: emotional self-awareness,emotional expression, emotional reasoning, emotional management of others, emotional self-control, and emotional awareness of others. It was concluded that civil status and type of profession are associated with EQ. Matore et al (2015) examinedrelationship of Adversity Quotient (AQ) and academic achievement among Malaysian polytechnic students. AQ contributed only $0.9 \%$ changes in the variance of academic achievement.

Synder et al (2004) creativity quotient accounts for fluency and flexibility in the task. It was concluded that CQ is very important when it comes to increase the creativity and innovation in the employees. Furnham (2016) studied the relationship between IQ, EQ and creativity and concluding Cognitive ability or IQ correlated positively but not significantly with creativity but significantly negatively with emotional intelligence. Jenaabadi (2015) aimed to examine the relationship of emotional intelligence and creativity with academic achievement indicating a high correlation between emotional intelligence and academic achievement and between creativity and academic achievement, but showing no significant difference was found between males and females considering their academic achievement. Ivcevic (2007) examined the relationship between emotional intelligence (EI) and emotional creativity (EC) and their effect on creative behavior. The results showed that EC, but not EI, would correlate with behavioral creativity and EI was uncorrelated with creative behavior.Loewen (2010) focused on psychometric properties of Empathy Quotient (EQ). The results show a high correlation with charitable giving and social demographics.

Aggarwal (2013) studied the link between Consciousness levels and performance. Consciousness quotient is very important to predict work performance. The various aspects for consciousness are social, emotional, self and mental consciousness. This paper focused on meditation and yoga to improve employee concentration levels and so that they feel more connected with their work Villagonzalo (2016) focused on cognitive intelligence, emotional, spiritual and adversity quotient and their effect on performance while concluding a positive relationship between intelligence quotient and the academic performance also having a high significant relationship between emotional quotient and the academic performance but a negative significant relationship between spiritual quotient and the academic performance and between adversity quotient and the academic performance.Eichinger (2015) focused on Intelligence Quotient, Technical/Operational Quotient, Motivational Quotient, experience Quotient, People Quotient and Learning Agility Quotient. This paper concluded that all these quotients are necessary for career success while four Q's i.e. TQ, XQ, PQ and LQ are important for career failure. 
Kumar et al (2013) focused on the relationship between EI and achievement motivation, psychological adjustment and scholastic performance of secondary school students concluding significant effect of EI on the achievement motivation and educational adjustment of students but EI having no significant effect on the emotional adjustment, social adjustment and scholastic performance of students.

\section{Critical review}

Emotional intelligence is very important for employees to maintain good interpersonal relationships both at personal and professional front. People with high EI tend to act as change agents as they are not afraid of change and can easily understand and adapt to the changing situations. They are self-aware and easily understand their own and other people's emotions and feelings. They know what is best for them and their optimal work environment and work style. They tend to be more empathetic and usually have an innate ability to understand what co-workers or clients are going through, they can get through difficult times drama free and can easily balance their work and life. People with EI know that perfection is impossible. People with high EI have an inborn senseof wonder and curiosity makes them delightful to be around. People with high EI know every day brings something to be thankful for and appreciate the small things in life. Intelligence quotient (IQ) plays a major role when analyzing the capability of an employee as well as it is an important factor for good academic performance. IQ is usually judged on the basis of verbal, non-verbal and logical reasoning. If a person has high IQ, he/she tends to have an intense attitude towards life and have a very complex personality which easily offends and irritates people as they can be difficult to understand at times, they usually have high concentration and tend to overthink and analyze things constantly in their head. They usually have an individualistic approach and usually do not perform well in teams. IQ tends to have a negative correlation with EI i.e.People with high IQ generally rate low on EI. Many studies have also proved that IQ alone cannot guarantee success and high performance and IQ accounts for only $20 \%$ when considering factors for success while EI tends to be the rest $80 \%$.If two job candidates have similar IQs, the one with the higher EI will likely be a better fit for the company.

Cultural quotient (CQ) plays a major role for any person to understand the differences and the characteristics of different cultures. A person with high CQ tends to easily understand the differences between difference cultures. It helps them to decrease the communication and collaboration gaps when working with people of different cultures. EI has a high correlation with CQ i.e. people with high EI have high CQ and are easily able to understand different cultures na d people. Studies also suggest not only high understanding but high level of cross border and cross cultural leadership is associated with high CQ which is very helpful for people at top positions in any MNC.Global quotient (GQ) is the ability of a person to be aware of diversity and be able to integrate and analyze across various diversities. GQ has a positive correlation with CQ and EI i.e. a person with high GQ tends to have high CQ and EI and has a positive relation between cultural and global leadership. A person with high CQ and GQ enhances leadership outcomes in a globalized environment. In today's world, in order to excel, companies need people with high CQ, GQ and EI to lead in this highly competitive and globalized scenario. Spiritual quotient (SQ)measures the social, investigative, artistic, realist and conventional aspect of the personality and also assesses how balanced a person is. People usually refer to it as the ultimate intelligence. It looks at EI the same way IQ looks at cognitive intelligence. People with high SQ tend to lead a more spiritual, balance and psychic life. A positive relationship has been noted between EI and SQ. Managers nowadays need to have a high EI and SQ in order to have more managerial effectiveness.

Adversity quotient (AQ) is the ability of a person to deal with adversity and high stress. AQ has a positive correlation with EI i.e. a person with a high AQ tends to deal with stress and adversity more easily as compared to that with people with low AQ. AQ is important as it helps the person to deal easily with stress and easily conquer problems and deal with adverse conditions. A person with high AQ is important but people with both high EI and AQ are more effective and efficient when considering high performance. Creativity quotient (CQ) measures the creativity and innovation of an employee or person. A person with high CQ has high creative and innovative abilities which becomes very important for people in highly creative jobs like artists, painters and top level mangers etc. IQ has a positive but not significant relationship with CQ which can be easily seen in people with high academic performance. People with high IQ and CQ tend to be creative and highly intelligent which is proven by many studies. CQ has a significant but negative with emotional intelligence.

Empathy quotient (EQ) measures the empathetic and charitable nature of the people. Empathy quotient has a high correlation with emotional intelligence. Although more research needs to be done in order to prove a positive correlation between the two. Although literature proves that a person with high EI tends to have high empathy as well as they are easily able to understand, appreciate and empathize with the people and understand the situations that they are in. The same stands true for meaning quotient and reputation quotient. Meaning quotient (MQ) focuses on how a sense of meaning and purpose can be fostered in the workplace and the level to which people find meaning in their work. Meaning quotient is still a relatively new concept and many studies have not been conducted to determine a valid relationship. Although it can be said that MQ has a positive 
relationship with IQ as MQ has a positive relationship with performance which also stands true for IQ. MQ is very important as when a business environment's MQ is low, employees put less energy into their work and see it as "just a job" that gives them little more than a paycheck which can be very harmful for any organization as it not only decreases the motivation of a person to work but also deteriorates the environment of the organization. Research needs to be done when considering reputation quotient (RQ). Very less information exists when considering the relationship between EI and RQ. Although it can be stated that RQ has the following aspects: Emotional Appeal, Products and Services, Vision and Leadership, Workplace and Environment, Social and Environmental Responsibility and Financial Performance Consciousness quotient (CQ) measures social, emotional, self and mental consciousness and how conscious the person is about his/her life, job and surrounding. It is very important to judge work performance as a person with high CQ denotes high performance. Although it is difficult to state the relationship between CQ and EI and more work needs to be done.

\section{Conclusion}

Emotional intelligence is very important for any person be it in personal and professional life. It helps to understand other people's emotions and feelings. High emotional intelligence helps the employees to be more self-aware which helps to understand co-workers and meet deadlines. People with high EI, can easily handle criticism, they tend to be more focused on outcomes, rather than feeling offended and take things to the heart. Concluding the relationships emotional intelligence has a negative correlation with intelligence quotient, emotional intelligence has a positive correlation with cultural quotient, global quotient has a positive correlation with cultural quotient and emotional intelligence, emotional intelligence has a positive relationship with spiritual quotient, emotional intelligence has a positive relationship with adversity quotient, intelligence quotient has a positive but not significantrelationship with creativity quotient,creativity quotient has a significant but negative with emotional intelligence.Empathy quotient has a high correlation with emotional intelligence. Meaning quotient has a positive relationship with intelligence quotient. When considering managers need to have high emotional intelligence, adversity quotient, cultural quotient, global quotient, spiritual quotient and empathy quotient, although high intelligence quotient is preferred. But when considering the employees in nonmanagerial positions, they need to have high spiritual quotient, high intelligence quotient and creativity quotient if in a creative or innovative job and high meaning quotient, although high EI is preferred.

\section{References}

[1]. Aggarwal, N. (2013). Measuring Consciousness Quotient -A Study of Its Influence on Employee's Work Performance and Organizational Outcomes, 2(11), 358-367.

[2]. Bemby Soebyakto, B., \& Wei Ming, C. (2012). An Empirical Testing of Intelligence, Emotional and Spiritual Quotients Quality of Managers using Structural Equation Modeling. International Journal of Independent Research and Studies, 1(1), 1-12. Retrieved from http://ssrn.com/abstract=2152029 \nwww.aiars.org/ijirs

[3]. Checa, P., \& Fernández-Berrocal, P. (2015). The role of intelligence quotient and emotional intelligence in cognitive control processes. Frontiers in Psychology, 6(DEC), 1-8. https://doi.org/10.3389/fpsyg.2015.01853

[4]. Cranston, A. (2014). Increasing the ' meaning quotient' of work, 1-8.

[5]. Denhardt, J. V, Campbell, K. B., Style, S., Finkelstein, S., Franc, E. C., Walle, V. De, Udayana, U. (2004). The 6 Qs of Leadership - A blueprint for enduring success at the top. Journal of Financial Economics, 3(4), 1-21. https://doi.org/10. 1108/IJLPS-07-20140011

[6]. Fallah, V., Khosroabadi, S., \& Usefi, H. (2015). Development of Emotional Quotient and Spiritual Quotient: The strategy of Ethics Development, 49, 43-52. https://doi.org/10.18052/www.scipress.com/ILSHS.49.43

[7]. Furnham, A. (2016). The Relationship between Cognitive Ability, Emotional Intelligence and Creativity. Psychology, 7(2), 193197. https://doi.org/10.4236/psych.2016.72021

[8]. Ghabanchi, Z., \& Rastegar, R. (2014). The correlation of IQ and emotional intelligence with reading comprehension. Reading Matrix: An International Online Journal, 14(2), 135-144. Retrieved from http://proxy1. ncu.edu/login?url=http://search. ebscohost. com/login. aspx ? direct=true $\& \mathrm{db}=\mathrm{ehh} \& \mathrm{AN}=99810568 \&$ site=eds-live

[9]. Gondal, U. H., \& Husain, T. (2013). A Comparative Study of Intelligence Quotient and Emotional Intelligence: Effect on Employees' Performance. Asian Journal of Business Management, 5(1), 153-162. Retrieved from http://search.ebscohost. com/login. aspx?direct=true \&db=bth\&AN=86149121\&site=ehost-live \&scope $=$ site

[10]. Horn, R. (2013). Is the Reputation Quotient a valid and reliable measure for corporate reputation? (December)

[11]. Imlahi, H. (2015). Intelligence quotient and its environmental factors in children. Spring.

[12]. Jenaabadi, H., Shahidi, R., Elhamifar, A., \& Khademi, H. (2015). Examine the Relationship of Emotional Intelligence and Creativity with Academic Achievement of Second Period High School Students, (August), 275-281.

[13]. Kumar, V. V. (2013). Effect of Emotional Intelligence on the Achievement Motivation, Psychological Adjustment and Scholastic Performance of Secondary School Students, 39(1), 2013.

[14]. Lievens, F., \& Chan, D. (2010). 16 Practical Emotional Intelligence, and Social Intelligence. Handbook of Employee Selection, (1995), 339-360. Retrieved from http://users.ugent.be/ flievens/practicallQ.pdf

[15]. Loewen, P. J., Lyle, G., \& Nachshen, J. S. (2010). An eight-item form of the Empathy Quotient (EQ) and an application to charitable giving, $1-14$.

[16]. Maiquez, R., Preolco, A. C., Sausa, L., \& Talatagod, K. (2015). Predictive ability of Emotional Intelligence and Adversity Quotient on academic performance of USC College students. Retrieved from http://peaklearning.com/documents/PEAK_GRI_sauza.pdf

[17]. Mohd Matore, M. E. E., Khairani, A. Z., \& Abd Razak, N. (2015). The influence of AQ on the academic achievement among Malaysian polytechnic students. International Educational Studies, 8(6), 69-74. https://doi.org/10.5539/ies.v8n6p69 
[18]. Sen, C., \& Yadav, L. (2016). Relationship between Spiritual Quotient and Managerial Effectiveness: A Study on Managers, 5(7), 2015-2017. https://doi.org/10.21275/v5i7.ART2016311

[19]. Stone, C., \& Stone, C. (2009). Emotional Intelligence: EQ vs. IQ, (June).

[20]. Tee, S., Chin, S., Anantharaman, R. N., Yoon, D., \& Tong, K. (2011). The Roles of Emotional Intelligence and Spiritual Intelligence at the Workplace. Journal of Human Resources Management Research, 2011, 1-9. https://doi.org/10.5171/2011.582992

[21]. Va, T. R. S. S. S. A. L. (2011). Beyond General Intelligence (IQ) and Emotional Intelligence (EQ) on Cross-Border Leadership Effectiveness in a Globalized World, 67(4). Retrieved from https://mail-attachment.google usercontent.com/attach ment/u/0/? $\mathrm{ui}=2 \& \mathrm{ik}=53 \mathrm{bad} 76 \mathrm{~b} 68 \& \mathrm{view}=\mathrm{att} \& \mathrm{th}=150 \mathrm{ab} 7 \mathrm{~d} 2 \mathrm{~b} 41 \mathrm{a} 4 \mathrm{f} 2 \mathrm{~b} \& \mathrm{attid}=0.1 \& \mathrm{disp}=$ inline\&realattid=f_ig9yrp5n1\&safe=1\&zw\&sadnir=1\& saddbat=ANGjdJ-yTVerBZQUHs_9jgFuaoe94A3q9gflyg0C9SwQ4YlaJ6a6wc-95H0c3Ffj8OncaZqswS

[22]. VanderPal, G. (2014). Global Leadership, IQ and Global Quotient. Journal of Management Policy \& Practice, 15(5), 120-134. Retrieved from http://proxy1.ncu.edu/logi n?url=http://search.ebscohost.com/login.aspx?direct=tru e\&db=bth\&AN=100 404876\&site $=$ eds-livelnhttp://content.ebscohost.com/ContentServer.asp?T=P\&P=AN\&K=100404876\&S=R\&D=bth\&Ebsco Conte $\mathrm{t}=$ dGJyMMvl7ESeprc4zOX0OLCmr02eqK9Sr6+4TbGWxWXS\&C

[23]. VILLAGONZALO, R. R. (2015). Intelligence Quotient, Emotional Quotient, Spiritual Quotient, and Adversity Quotient ${ }^{\circledR}$ and the Academic Performance of Students. Statewide Agricultural Land Use Baseline 2015, 1(March). https://doi. org/10. 1017/CBO9781107415324.004

[24]. Zekânın, K., Liderlik, K., Üzerindeki, E., İşletmelerinde, K., \& Bir, N. (2014). The Role of Cultural Intelligence in Cross-Cultural Leadership Effectiveness: A Qualitative Study in the Hospitality Industry 1, 9(35), 6099-6108.

[25]. Snyder, A., Mitchell, J., Bossomaier, T., \& Pallier, G. (2004). The Creativity Quotient. Creativity Research Journal, 16(4), 415-420.

[26]. EMOTIONAL INTELLIGENCE AND ADVERSITY QUOTIENT OF SELECTED HELPING PROFESSIONALS A Master Thesis Submitted to the Department of Psychology Institute of Arts and Sciences Far Eastern University - Manila in Partial Fulfillment of the Requirements for the deg. (2015), (November)

[27]. W. Eichinger, R., \& M. Lombardo, M. (2015). The 6 Qs of Leadership - A blueprint for enduring success at the top, (October).

[28]. Ivcevic, Z., Brackett, M. A., \& Mayer, J. D. (2007). Emotional intelligence and emotional creativity. Journal of Personality, 75(2), 199-235. https://doi.org/10.1111/j.1467-6494.2007.00437.x 